\title{
Goethe e Brecht em diálogo
}

Eloá Heise ${ }^{1}$

\begin{abstract}
The purpose of this paper is to compare two prologs, namely 'Prolog im Himmel' in Faust I and the prolog in Der gute Mensch von Sezuan by Brecht. The comparative analysis of the two texts provides evidence to state that Brecht produces a parody of Goethe's prolog. This procedure is interpreted here as a feature of $20^{\text {th }}$ century literature. Intertextuality and recreation are seen as a way to characterize a shapeless present and are approached by drawing an analogy and critically comparing and contrasting Brecht's prolog to a literary masterpiece.
\end{abstract}

Keywords: Goethe; Brecht; parody; intertextuality

Resumo: O propósito desse trabalho é tecer um paralelo entre os prólogos do Faust $I$, o "prólogo no céu" de Goethe e o prólogo da peça de Brecht Der gute Mensch von Sezuan. A análise comparativa dos dois textos oferece subsídios para se afirmar que Brecht cria uma paródia do prólogo goethiano, procedimento que será interpretado como uma das características da literatura do século XX. Tal recurso de intertextualidade e de recriação será visto como uma forma de caracterizar o presente amorfo a partir do confronto e da analogia, com visão crítica, de uma obra consagrada da tradição.

Palavras-chave: Goethe; Brecht; paródia; intertextualidade

Pretende-se tecer aqui um paralelo entre os prólogos de duas obras da dramaturgia alemã, Der gute Mensch von Sezuan, de B. Brecht e o Faust I de Goethe. Os termos do próprio título da peça de Brecht “der gute Mensch” constituíram o mote inspirador para essa comparação, uma vez que remetem à fala do Senhor no "prólogo no céu” no Fausto I, quando o Senhor, ao discutir com Mefistófeles o destino do homem, afiança de forma categórica: “Ein guter Mensch in seinem dunklen Drange/ Ist sich des rechten Weges wohl bewusst”(328,329)(GOETHE 2004: 54) ${ }^{2}$ A análise comparativa entre os dois prólogos, tem como propósito não apenas apontar as convergências e divergências entre os dois autores na abordagem de um tema equivalente, mas propõese também colocar em foco uma das características marcantes da literatura do século XX: a problematização do presente em analogia e transgressão ao passado. Assim, o olhar de Brecht volta-se para tradição como instrumento auxiliar para desenhar o perfil da nova realidade. A distância entre o ontem e o hoje, a tensão que separa a obra

\footnotetext{
${ }^{1}$ Professora Doutora no Departamento de Letras Modernas da Faculdade de Filosofia, Letras e Ciências Humanas da Universidade de São Paulo: eloaheise@ajato.com. br

${ }^{2}$ Grifo meu. Os números entre parênteses após as citações de Goethe correspondem aos números dos versos da tragédia Fausto. A tradução correspondente é da autoria de Jenny Klabin Segall extraída do livro Fausto. Uma tragédia, primeira parte. Editora 34, São Paulo, 2004. "Que o homem de bem, na aspiração que, obscura o anima/da trilha certa se acha sempre a par.” p. 55.
} 
evocada de sua recriação produz um terceiro elemento, que faz com que tanto o espelho quanto o modelo passem por um processo de estranhamento.

\section{O homem em debate}

A peça de Brecht Der gute Mensch von Sezuan foi escrita durante a emigração, entre os anos de 1938-1940. A primeira versão data de 39 e a segunda de 41. Sua primeira encenação deu-se na Suíça, em Zurique, em 1943, palco de resistência para apresentação de textos alemães durante os anos sombrios do nazismo. O texto é, ainda hoje, um dos mais encenados e Brecht que nele se mostra, nas palavras de Hans MEYER, "um poeta da humanidade” (Cf. BRÄUTIGAM 1970). Essa caracterização deve, no contexto argumentativo desse debate, ser entendida no sentido de colocar em questão as potencialidades e faculdades do ser humano, seu livre-arbítrio diante de pretensos poderes transcendentes, ou diante dos condicionamentos naturais e históricos.

O cerne dessa peça, como o título bem indica, é o ser humano, a quem deve ser permitido ser bom. Sob este ângulo temático, podemos afirmar que Brecht é, aqui, como Goethe no Faust I, um clássico. Clássicos não só como representantes modelares das letras germânicas, mas, levando-se em conta o enfoque de análise precípuo que se pretende engendrar, clássicos por abordarem questões que dizem respeito ao homem como um todo, elevando o individual e local ao universal e extemporâneo. Nas obras em questão, os dois autores discutem o papel do ser humano, dividido entre o bem e o mal. No caso específico da obra de Brecht, ao espectador não é oferecida uma solução para o impasse; no fim da peça ele é confrontado com a pergunta que paira, sem resposta, no epílogo: “ Auf welche Weis dem guten Menschen man/Zu einem guten Ende helfen kann.” (BRECHT1961: 160) ${ }^{3}$. Paralelamente discute-se e procura-se pela bondade, o ideal que deveria ser a suprema felicidade sobre a terra. Essas idéias norteadoras já indicam o quanto o autor, neste texto, se mostra um humanista no sentido mais profundo. A discussão dialética que se propõe face à existência humana é a contraposição entre “querer ser bom” e “não poder ser bom”, pois o ser humano bom vive em um mundo ruim. Já na obra de Goethe, Fausto, o representante da humanidade, é colocado no jogo universal, entre o bem e o mal, entre o céu e o inferno, como objeto demonstrativo do poder e do sentido da criação. O Senhor vê na existência um plano,

\footnotetext{
3 “de que maneira se pode ajudar/ uma boa alma a chegar a um bom fim.” BRECHT, B. Der gute Mensch von Sezuan, Berlin, Suhrkamp Verlag, 1961, p. 160.
} 
crescimento e amadurecimento: "Weiss doch der Gärtner, wenn das Bäumchen grünt,/Dass Blüt' und Frucht die künft'gen Jahre zieren”(310/311) (GOETHE 2004: $52)^{4}$, Mefistófeles, em contraposição enxerga o homem como uma criatura muito mal construída, na busca pelas mais lindas estrelas e pelo gozo mais profundo. A resposta para essa oposição só será intuída pelo espectador/leitor com o possível desfecho da aposta entre essas duas forças, uma vez que no drama de Goethe se estabelece um embate típico do teatro barroco: a luta entre o céu e o inferno por uma alma humana.

\section{Prólogos em contraponto}

Afirmou-se, anteriormente, que as duas peças teatrais são precedidas de um prólogo. Resta aqui enfatizar que, no caso da peça de Goethe, o foco de análise se dirige, especificamente, a um dos prólogos, o "Prólogo no céu”, uma espécie de moldura de ordem metafísica que envolve e arremata a busca terrena de Fausto pelo absoluto e, em última análise, pelo sentido da vida. Já Brecht, em seu prólogo, movimenta-se no âmbito da imanência, afastando-se da busca por solução na esfera transcendente. Esta parte das obras que nos dois autores desenvolve-se em planos distintos, a esfera metafísica em Goethe e o mundo imanente em Brecht, desempenha, nos dois contextos, não apenas um papel introdutório, mas adquire a função de exposição, pois o principal debate já é apresentado, de forma condensada. Se em Goethe afirma-se o sentido da criação, louvada como bela e digna pelos anjos, em Brecht o mundo é feio e ruim; não há mais temor a Deus e aqueles deuses que descem à terra para ajudar são alienados e propõem uma salvação irrealizável.

Na essência, os temas colocados em debate são os mesmos, mas com sinais invertidos. Enquanto em Goethe o jogo entre bem e mal adquire o caráter de uma teodicéia, ou seja, procura-se justificar a bondade divina contra os argumentos sobre a existência do mal no mundo, os deuses de Brecht são fracos e impotentes, com características por demais humanas para conseguirem ajudar os homens.

Contudo, não se pode afirmar, de maneira unívoca e simples, que Goethe oferece uma visão positiva da criação enquanto Brecht oferece a seu público uma percepção objetiva; crítica e desoladora do mundo. A visão do homem e do universo, apresentada

\footnotetext{
4 “Quando verdeja o arbusto, o cultor não ignora/ Que no futuro fruto e flor produz” (GOETHE 2004: 53)
} 
por Goethe, mesmo sendo positiva, não deixa de refletir matizes contrastantes. Essa oposição se dá na contraposição entre as concepções de Mefistófeles e do Senhor.

Enquanto os anjos entoam loas à harmonia entre as esferas, afirmando que as mais elevadas obras estão tão magníficas como no primeiro dia, Mefisto não tem altas considerações a fazer sobre o sol ou sobre o mundo; só vê como o homem se atormenta e a terra está tão ruim como sempre. Para o diabo, a razão, a chama divina concedida ao homem pelo céu, só o transforma em animal mais animalesco que outros animais; sua vida, sempre igual, não consegue alçar nenhum vôo além do chão e acaba sempre chafurdando na lama:

\author{
Er scheint mir, mit Verlaub von von Euer Gnaden, \\ Wie eine der langbeinigen Zikaden, \\ Die immer fliegt und fliegend springt \\ Und gleich im Gras ihr altes Liedchen singt; \\ Und läg er nur noch immer in dem Grase! \\ In jeden Quark begräbt er seine Nase. (287-292).(GOETHE 2004: 50) ${ }^{5}$
}

O Senhor, sem negar os erros humanos, admite que o homem erra em sua aspiração infinita, “Es irrt der Mensch solang’ er strebt”(327) (GOETHE 2004: 54) ${ }^{6}$ mas, a boa alma, em seu ímpeto obscuro, está instintivamente consciente do caminho certo.

Eis aqui uma diferença fulcral entre Goethe e Brecht. A boa alma em Goethe está predestinada ao caminho certo. Oscilando entre forças polares da ação e da inércia (SUDAU 1993: 60), o homem, por ser intrinsecamente bom, está destinado ao desenvolvimento, indo da confusão à clareza das idéias: “Wenn er mir jetzt auch nur verworren dient/ So werd' ich ihn bald in die Klarheit führen” (GOETHE 2004:52) ${ }^{7}$. O senhor está seguro que seu botão se transformará em fruto. Já o ser humano bom em Brecht está cheio de dúvidas: "Halt, Erleuchtete, ich bin gar nicht sicher, dass ich gut Bin. Ich möchte es wohl sein, nur, wie soll ich die Miete bezahlen?” (BRECHT 1961: $17)^{8}$; No fim, é abandonado pelos deuses, que acreditam ter realizado sua missão. Em franca oposição a Goethe, a única boa alma encontrada pelos deuses na peça de Brecht, não está destinada à redenção, mas é desamparada, ficando à mercê do mal, fruto de

\footnotetext{
5 “Parece, se me permite Vossa Graça,/Um pernilongo gafanhão que esvoaça/Saltando e vai saltando à toa/E na erva a velha cantarola entoa;/E se jazesse ainda na erva o tempo inteiro!/Mas seu nariz enterra em qualquer atoleiro".

6 “Erra o homem enquanto a algo aspira.” (GOETHE 2004:55)

7 "Se em confusão me serve ainda agora/Daqui e, breve o levarei à luz” (GOETHE 2004:53)

${ }^{8}$ Esperai, iluminados, não estou segura de que sou boa. Eu gostaria de ser, só que, como vou pagar meu aluguel?”(BRECHT 1961:17)
} 
uma ordem social injusta: “Oh, entfernt euch nicht Erleuchtete! Ich habe noch nicht alles gesagt! Ich brauche euch drigend! (BRECHT 1961: 158) ${ }^{9}$.

Em termos gerais, o “prólogo no céu” de Goethe pode ser percebido como o inverso do prólogo brechtiano. Em Brecht a peça se inicia com a essa parte introdutória que, como já foi dito, assume a função de exposição e, no caso do criador do teatro épico, tem a tarefa precípua de romper a ilusão de uma representação dramática. Assim, o aguadeiro Wang apresenta-se diante do pano de boca, separando-se do papel de sua personagem na peça e assumindo, claramente, a função de narrador. Ao espectador é narrada a situação de pobreza que reina na província, bem como as queixas dos homens aos céus, pois o mundo se mostra muito ruim para se viver. Nesse quadro de miséria e lamentações parece que só os deuses poderiam ajudar. Consta que o céu, intranqüilo com tantos queixumes, mandou alguns dos seus mais elevados deuses para salvar a terra. Procuram uma boa alma, uma missão fundamental para a preservação do mundo, pois: "In dem Beschluss hiess es: die Welt kann bleiben, wie sie ist, wenn genügend gute Menschen gefunden werden, die ein menschenwürdiges Dasein leben können” (BRECHT 1961: $10 / 11)^{10}$. Portanto, a condição sine qua non para que o mundo permaneça como está reside na possibilidade de serem encontrados seres humanos que possam viver uma existência humanamente digna Essa cláusula estabelecida pelos deuses empresta uma força especial a essa condicionante, em outros termos, é preciso "ser bom” e “viver com dignidade”, posições de coexistência impraticável, ou melhor, parecem excluir-se mutuamente.

Já a primeira descrição dessas criaturas que, em princípio, deveriam ser divinas, é uma maneira de estranhá-las perante o espectador: "Sie sind wohlgenährt, weisen kein Zeichen irgendeiner Beschäftigung auf (...) kommen also von weit her.” (BRECHT 1961: 8). ${ }^{11}$. Eis uma descrição que mais se aplica a burgueses bem nutridos, ociosos e distantes deste mundo de miséria. Em contraposição a esta visão dos deuses alienados em relação aos infortúnios da terra, o primeiro Deus, representante declarado da missão a ser cumprida, é o que, indiretamente, parece constatar a verdadeira situação do mundo, ecoando, assim, a hipotética solução insuflada por Brecht: “Seit zweitausend

\footnotetext{
9 “ Oh, não vos afastei, iluminados Ainda não disse tudo! Preciso urgentemente de vós! (BRECHT 1961: 159)

10 "Na resolução consta: o mundo pode permanecer tal com é, se forem encontrados seres humanos suficientes que possam viver uma existência humanamente digna.” (BRECHT 1961: 10/11)

11 "Eles estão bem alimentados, não mostram nenhum sinal de qualquer ocupação (...) e vêm de longe." (BRECHT 1961:8).
} 
Jahren geht dieses Geschrei, es gehe nicht weiter mit der Welt, so wie sie ist ."(BRECHT 1961: 11$)^{12}$

À guisa de súmula pode-se representar de maneira esquemática os pontos levantados na comparação dos dois prólogos.

Prólogos em contraponto

Equivalências: Tema: relação do homem com Deus, bem, mal, mundo. Função : introdução, exposição (debate principal condensado)

Contraposições:

\section{Brecht}

mundo: feio, ruim domina a pobreza os bons vão mal vida difícil

homem: abandonado pelos deuses o bom à mercê do mundo mau trajetória terrena procura viver dignamente

mal: fruto de uma ordem social injusta

\section{Goethe}

mundo: sentido positivo da criação harmonia cósmica domínio do bem

homem: conduzido por Deus erra, mas é na essência bom rumo a esferas mais elevadas

mal : (Mefisto) impulsiona o homem $=$ instrumento do bem

Para o humanismo de Goethe o mal, representado por Mefisto, está subordinado a Deus, o que o transforma em um instrumento do bem. O bem e o mal, como força e contra-força, representam a polaridade cósmica que impele o homem a tentar ultrapassar os limites do mundo para galgar esferas mais elevadas. Seu trajeto é o da intensificação (Steigerung), mesmo que não alcance o conhecimento absoluto. Em Brecht o homem está preso aos limites terrenos. O mal não está sujeito a uma força organizadora maior, um "Senhor", como no caso de Goethe, mas é uma ameaça que subjuga a boa alma, indefesa, sem a proteção divina. Em lugar da harmonia cósmica, Brecht mostra a injustiça social e o homem, sem aspirar pelo absoluto, quer apenas um lugar dignamente humano na sociedade.

\footnotetext{
12 “Há dois mil anos há este clamor de que não dá para continuar com o mundo como ele é.” (BRECHT 1961: 11)
} 


\section{Jogo de espelhos invertidos}

No Faust, há um diálogo entre Fausto e Mefistófeles em que o diabo aponta, com a sua percepção contundente e jocosa, a paródia como o princípio da modernidade. A rigor, pode-se concordar com o velho diabo e afirmar que existe uma consonância entre paródia e modernidade. A paródia moderna, contudo, diferencia-se da tradição literária e filosófica dominante à época de Goethe (Iluminismo, Sturm und Drang e Classicismo), quando a prática de recorrer a modelos anteriores, deixando claro a origem do empréstimo, era aceita e bem-vinda, pois pressupunha a exaltação e a homenagem a uma obra de significado maior. Esta prática foi abandonada a partir do Romantismo, quando a tônica deslocou-se da obra para o autor e este, como criador genial, tinha na originalidade o primeiro mandamento para a sua criação artística. Mas essa dita “originalidade” não desaparece quando o texto, na busca por um efeito de linguagem, adquire seu próprio contorno através de um jogo intertextual. Este é o caso da paródia moderna, um exercício de criação, quando um texto evoca outro texto, num jogo de espelhos invertidos (Cf. SANT’ANNA 1985). Esses textos parodísticos, tão recorrentes na arte contemporânea, representam uma maneira nova de ler o convencional, mais precisamente, uma retomada a partir de uma conscientização crítica. Essa nova maneira de ler um texto da tradição significa um "ato de insubordinação contra o simbólico” (SANT’ANNA 1985: 32) que traz consigo um gesto de individualidade A criação se concretiza na medida em que não se quer apenas descrever, mas também indicar, rememorar, integrar e, paralelamente, colocar em xeque o obra referida; nesse nexo a poesia não apenas “copia” um conteúdo já existente, ela também reúne e, em um exercício dialético, dispersa.

Na modernidade, os meios tecnológicos destruíram as distâncias. As formas artísticas, impotentes diante da vastidão de mundo, procuram pontos de apoio que as auxiliem a dar contornos a esse universo sem perfil definido. A pluralidade e a simultaneidade, palavras mágicas do nosso tempo, relativizaram de tal maneira o presente, que este se tornou amorfo e imperscrutável como fonte de pesquisa. Trava-se, assim, um diálogo com o passado na procura de explicação para o presente, mas essa evocação, plena de conhecimento irônico daquilo que foi, acaba por projetar, numa busca utópica, os contornos do que poderia ser. Toma-se o passado como caminho indicador do futuro, uma vez que o presente é, por demais, fluido e enigmático. 
Movimenta-se no espaço do passado, do mito, da retrospecção ou do futuro, da utopia, da prospecção.(Cf. JENS 1964)

\section{O diálogo com os clássicos}

Brecht, em seu engajamento marxista, busca uma criação literária funcional, com o objetivo de mobilizar seus leitores. Para tanto, trava um diálogo consciente com a tradição literária, sobretudo a alemã, no sentido de suscitar, na mesma esteira do sentido moral típico das obras clássicas (segundo Horácio, a obra clássica deveria ser dulce et utile),(RosenFELD 1999: 375) tomadas de posição capazes de darem conta das demandas da realidade. O poeta alemão tem consciência de que os clássicos são uma possibilidade de concretização de parte de nossas utopias, não só por serem modelos exemplares, mas também por fazerem das utopias humanas, prenhes de significado universal, o seu assunto, sempre pulsante. O autor percebe, assim, a força social e mobilizadora presente nos clássicos e, num diálogo crítico com estes modelos literários, angaria também para sua criação esse traço universal das utopias.

Ao estabelecer uma intertextualidade com textos clássicos, Brecht, tacitamente, reconhece-lhes a importância como referência da cultura escrita e, por conseqüência, como produto de matéria coletiva. Cabe, contudo, resgatar nesses modelos o que há neles de novo, surpreendente, produtivo. O debate atual enriquecido com a integração dos clássicos torna-os livres de idealizações e, a partir de uma leitura crítica, recoloca-os ao nível de obras vivas da cultura européia. Ao incorporá-los, de forma evidente ou tácita, Brecht lhes rende uma homenagem, os transgride e os revitaliza ao mesmo tempo em que angaria também para si, a comunicabilidade que tanto almeja e, em última análise, também o estatuto de clássico.

Mas a humanidade de Brecht não é aquela dos clássicos. Se a utopia de Goethe se expressa na crença humanística e fé profunda no equilíbrio universal, através da cosmovisão de uma polaridade harmoniosa e se Schiller vê na experiência estética o sinônimo de liberdade, o marxista Brecht tem consciência que o bem, que se procura, pertence a um mundo vindouro, portanto no reino da utopia. A harmonia clássica entre o mundo e o homem é algo estranho a Brecht que vê como sua tarefa provocar e deixar claro ao espectador as contradições da vida, sem acreditar numa polaridade harmoniosa, como Goethe. Para esses dilemas não se apontam soluções e cabe ao público prosseguir, 
por si só, no seu processo de educação: “Den Vorhang zu und alle Fragen offen (...) Soll es ein andrer Mensch sein? Oder eine andere Welt?/Vielleicht nur andere Götter? Oder keine?” (BRECHT 1961: 160) ${ }^{13}$.

\section{Referências bibliográficas}

BräUtigam, Kurt. Bertolt Brecht. Der gute Mensch von Sezuan. München, R. Oldenbourg Verlag, 1970.

Brecht, Bertolt. Der gute Mensch von Sezuan. Berlin, Suhrkamp Verlag, 1961.

Goethe, Johann Wolfgang von. W. Fausto. Uma Tragédia. São Paulo, Editora 34, 2004.

JEns, Walter. Deutsche Literatur der Gegenwart. München, Deutscher Taschenbuch Verlag (dtv), 1964.

Rosenfeld, A./ Guinsburg, J. Um conceito de classicismo. In GuinsBurg, J. (Org.) $O$ Classicismo. São Paulo, Editora Perspectiva, 1999, 373-375.

Sant’Anna, Affonso Romano. de. Paródia, Paráfrase \& Cia. São Paulo, Editora Ática S.A., 1985.

SuDAU, Ralf. Faust I und Faust II. München, Oldenbourg Verlag GmbH, 1993.

\footnotetext{
13 “A cortina fechada e as perguntas abertas (...) Devia ser outro o ser humano? Ou um outro mundo? / Talvez só outros deuses? Ou nenhum? (BRECHT 1961: 160)
} 